\title{
Effect of hydrogen on the growth of thin hydrogenated amorphous carbon films from thermal energy radicals
}

\section{Citation for published version (APA):}

Neyts, E., Bogaerts, A., \& Sanden, van de, M. C. M. (2006). Effect of hydrogen on the growth of thin hydrogenated amorphous carbon films from thermal energy radicals. Applied Physics Letters, 88(14), 1419221/3. [141922]. https://doi.org/10.1063/1.2193803

DOI:

$10.1063 / 1.2193803$

Document status and date:

Published: 01/01/2006

\section{Document Version:}

Publisher's PDF, also known as Version of Record (includes final page, issue and volume numbers)

\section{Please check the document version of this publication:}

- A submitted manuscript is the version of the article upon submission and before peer-review. There can be important differences between the submitted version and the official published version of record. People interested in the research are advised to contact the author for the final version of the publication, or visit the $\mathrm{DOI}$ to the publisher's website.

- The final author version and the galley proof are versions of the publication after peer review.

- The final published version features the final layout of the paper including the volume, issue and page numbers.

Link to publication

\section{General rights}

Copyright and moral rights for the publications made accessible in the public portal are retained by the authors and/or other copyright owners and it is a condition of accessing publications that users recognise and abide by the legal requirements associated with these rights.

- Users may download and print one copy of any publication from the public portal for the purpose of private study or research.

- You may not further distribute the material or use it for any profit-making activity or commercial gain

- You may freely distribute the URL identifying the publication in the public portal.

If the publication is distributed under the terms of Article 25fa of the Dutch Copyright Act, indicated by the "Taverne" license above, please follow below link for the End User Agreement:

www.tue.nl/taverne

Take down policy

If you believe that this document breaches copyright please contact us at:

openaccess@tue.nl

providing details and we will investigate your claim. 


\title{
Effect of hydrogen on the growth of thin hydrogenated amorphous carbon films from thermal energy radicals
}

\author{
E. Neyts ${ }^{a)}$ and A. Bogaerts \\ University of Antwerp, Universteitsplein 1, B-2610 Antwerp, Belgium \\ M. C. M. van de Sanden \\ Department of Applied Physics, Eindhoven University of Technology, Den Dolech 2, 5600 MB Eindhoven, \\ The Netherlands
}

(Received 1 December 2005; accepted 26 February 2006; published online 6 April 2006)

\begin{abstract}
Molecular dynamics simulations have been performed to investigate the growth of thin hydrogenated amorphous carbon $(a-\mathrm{C}: \mathrm{H})$ films from radical species with thermal energy. It is found that the incorporation of $\mathrm{H}$ into the film increases the mass density. The maximum mass density is reached for a $\mathrm{H}$ flux of about $10 \%$. The atom density of the films reaches a maximum at a $\mathrm{H}$ flux of about $30 \%$. It is shown that these effects are a result of the change in microstructure of the films, including a $\mathrm{H}$-induced $s p$ to $s p^{2}$ to $s p^{3}$ shift. These results are important for thin $a-\mathrm{C}: \mathrm{H}$ film deposition techniques where chemisorption of radical species is the main growth mechanism. (C) 2006 American Institute of Physics. [DOI: 10.1063/1.2193803]
\end{abstract}

Hydrogenated amorphous carbon $(a-\mathrm{C}: \mathrm{H})$ films can be deposited in a large variety of forms, exhibiting a diversity of physical and chemical properties. These properties are determined by the respective proportions of $s p^{2}$ and $s p^{3}$ carbon sites, controlling the microstructure of the film. ${ }^{1}$ The hydrogen incorporation in the film is one of the key quantities determining these $s p^{2}$ and $s p^{3}$ proportions. $^{2-4}$ In order to better understand how $\mathrm{H}$ is incorporated into a growing film, and how this $\mathrm{H}$ incorporation influences the microstructure of the deposited $a-\mathrm{C}: \mathrm{H}$ films, we present a series of simulations in which thin $a-\mathrm{C}: \mathrm{H}$ films were deposited under identical conditions, varying only the $\mathrm{H}$ flux towards the substrate.

The model used in these simulations is based on the Brenner potential for hydrocarbons, ${ }^{5}$ and was originally developed by Tanaka et al. ${ }^{6}$ A clean diamond $\{111\}$ surface is exposed to consecutive particle impacts. Each impact was followed for $2 \mathrm{ps}$, applying a heat bath set at $100 \mathrm{~K}$ during the last $0.4 \mathrm{ps}$. The output of every impact is the input for the next impact. After each impact, unbound atoms are removed from the configuration. Growth was continued until the films reached a thickness of about $10 \mathrm{~nm}$, each containing about 4000 atoms. After the growth phase, the films were allowed to relax for $10 \mathrm{ps}$. A more detailed description of the model can be found elsewhere. ${ }^{7}$

Conditions were chosen to simulate deposition systems in which chemical growth by radical species is the dominant growth mechanism. An example is the class of remote plasma sources when no substrate bias is applied, e.g., for deposition of thin films on plastics. Therefore, we have chosen to base our simulations on experimentally measured particle fluxes in an expanding thermal plasma (ETP) in which no substrate bias was applied. ${ }^{8}$ The relative particle fluxes as used in our model are given in Table I. The hydrogen flux towards the substrate, however, could not be measured experimentally, and will therefore be varied in this study. We have chosen to allow an additional $\mathrm{H}$ particle flux towards the growing surface in the range between $0 \%$ and $45 \%$ of the

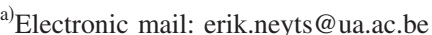

total impacting particle flux. Here, we define the $\mathrm{H}$ particle flux as the number of $\mathrm{H}$ impacts on the surface divided by the total number of particle impacts. In total, 13 films have been deposited.

Since the kinetic energy of the radicals is very low $(0.13 \mathrm{eV})$, the subplantation mechanism does not occur, and the only process contributing to growth of the film is chemical reactions at the surface, i.e., chemisorption. This process is dependent on the structure of the surface itself. Hence, a given radical can react differently on different surfaces, leading to different films. ${ }^{9}$ As the relative $\mathrm{H}$ flux towards the substrate increases, the $\mathrm{H}$ content in the film increases proportionally. There is an almost linear correspondence between the $\mathrm{H}$ flux and $\mathrm{H}$ incorporation in the film, as can be seen in Fig. 1 (see inset). Vice versa, the H flux towards the substrate can thus be estimated from the measured $\mathrm{H}$ content in the film. Also, the $\mathrm{H}$ distribution among the $\mathrm{C}$ atoms in the films is directly related to the $\mathrm{H}$ content, as can be seen in Fig. 1. Here, the calculated fractions of $\mathrm{C}, \mathrm{CH}$, and $\mathrm{CH}_{2}$ groups in the films are shown as a function of the $\mathrm{H}$ content. The fraction of $\mathrm{C}$ atoms carrying both one and two $\mathrm{H}$ atoms increases as the $\mathrm{H}$ flux towards the substrate increases. The fraction of chain-terminating $\mathrm{CH}_{3}$ groups was found to be negligible in all simulated films.

High hydrogen fluxes make the resulting structure more porous and less dense, as will be shown below. The decrease in mass density of $a-\mathrm{C}: \mathrm{H}$ films with increasing $\mathrm{H}$ content has already been shown-see, e.g., the study by Ferrari et al. for films containing more than $40 \% s p^{3}$ content, $^{3}$ and references therein. In Fig. 2, it is shown that this effect also occurs under the conditions used in this study for high enough $\mathrm{H}$ fluxes. The figure shows the calculated mass density and atom density of the different films as a function of the $\mathrm{H}$ content in the bulk of the film. At low $\mathrm{H}$ fluxes, the mass density increases as a function of $\mathrm{H}$ flux (or $\mathrm{H}$ content), until a maximum is found at a $\mathrm{H}$ content of about $10 \%$. The atom density, however, continues to increase as a function of the $\mathrm{H}$ content. Indeed, a high hydrogen flux allows the incorporation of a large $\mathrm{H}$ fraction into the carbon matrix, increasing the atom density. This, however, does not increase the mass 
TABLE I. Relative fluxes for the different C-containing growth species as obtained from experiment. (Ref. 8). $\Phi_{\mathrm{H} \text {,rel }}$ denotes the relative $\mathrm{H}$ flux, varied in the range between 0.0 and 0.45 .

\begin{tabular}{ll}
\hline \hline Species & Relative flux \\
\hline $\mathrm{C}$ & $0.71\left(1-\Phi_{\mathrm{H}, \mathrm{rel}}\right)$ \\
$\mathrm{CH}$ & $0.05\left(1-\Phi_{\mathrm{H}, \mathrm{rel}}\right)$ \\
$\mathrm{C}_{2}$ & $0.20\left(1-\Phi_{\mathrm{H}, \mathrm{rel}}\right)$ \\
$\mathrm{C}_{2} \mathrm{H}$ & $0.04\left(1-\Phi_{\mathrm{H}, \mathrm{rel}}\right)$ \\
\hline \hline
\end{tabular}

density due to the low hydrogen mass. A maximum in the atom density is found at a $\mathrm{H}$ content of about $22 \%$, corresponding to a $\mathrm{H}$ flux of about $30 \%$, according to Fig. 1 . The occurrence of bulky $\mathrm{CH}_{2}$ groups at high $\mathrm{H}$ fluxes (see Fig. 1) accounts for the decrease in both the mass density and atom density at a $\mathrm{H}$ content $>25 \%$. Also, as more $\mathrm{H}$ is incorporated into the film, relatively less $\mathrm{C}$ atoms must accommodate relatively more $\mathrm{H}$ atoms, increasing the average carbon coordination number, in the range of $2.8-3.1$ for a $\mathrm{H}$ particle flux varying from $0 \%$ to $45 \%$.

Hydrogen also changes considerably the microstructure of the films. In Fig. 3, the evolution of the $s p^{1}, s p^{2}$, and $s p^{3}$ $\mathrm{C}$ sites in the bulk of the film is plotted as a function of the $\mathrm{H}$ content. Here, a carbon site is designated $s p^{1}$ if the carbon atom is one or two coordinated. Likewise, $s p^{2}$ sites and $s p^{3}$ sites are identified as three-coordinated and four-coordinated $\mathrm{C}$ atoms, respectively. It can be seen in the figure that low $\mathrm{H}$ fluxes lead to a lowering of the $s p^{1}$ content, an increase in the $s p^{2}$ content, and a slight increase in the $s p^{3}$ content. This transition from $s p^{1}$ to $s p^{2}$ as a function of the $\mathrm{H}$ content in the film coincides with the maximum in the mass density. In this region, the film structure is composed of a network of $s p^{2}$-like C-C bonds, stabilized by chemical resonance. As the $s p^{1}$ sites occupy a larger volume per atom than $s p^{2}$ sites $\left(s p^{1}\right.$ sites are linear one-dimensional structures while $s p^{2}$ sites are two dimensional), the $s p^{1}$ to $s p^{2}$ transition effectively lowers the volume per atom, and hence increases the mass density.

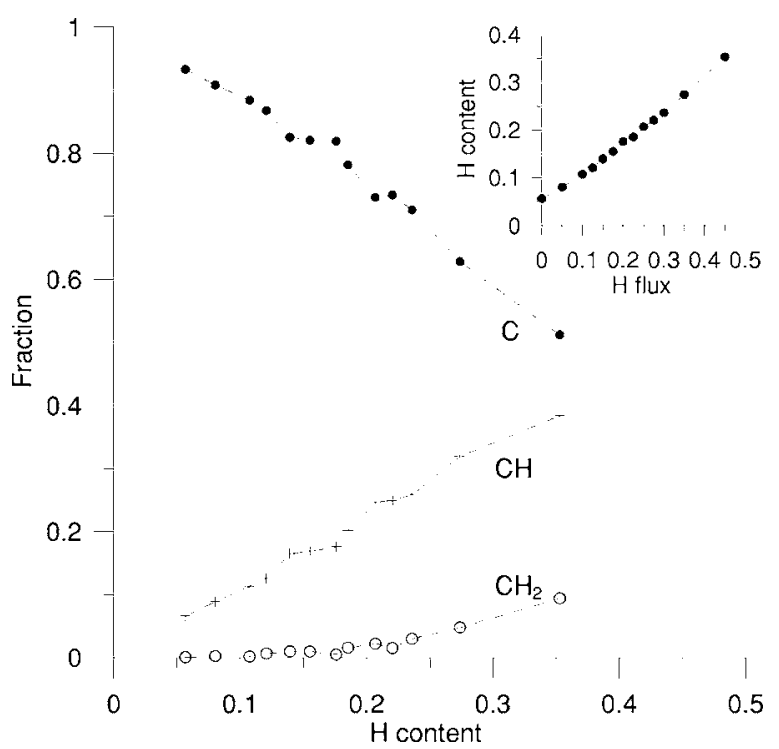

FIG. 1. Calculated hydrogen distribution among the $\mathrm{C}$ atoms as a function of the $\mathrm{H}$ content in the film; the calculated $\mathrm{H}$ content in the films as a function of the H flux is shown in the inset.

Downloaded 11 Sep 2007 to 131.155.108.71. Redistribution subject to AlP license or copyright, see http://apl.aip.org/apl/copyright.jsp

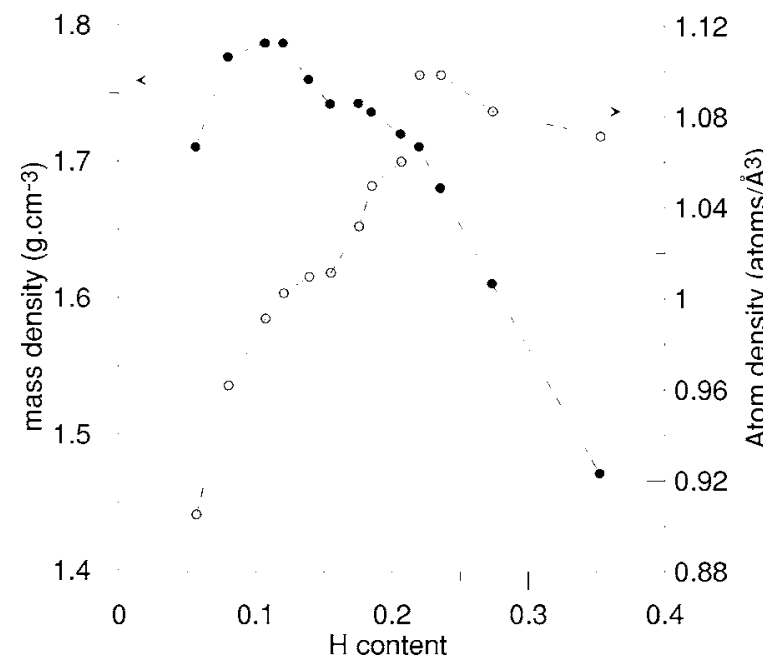

FIG. 2. Calculated mass densities and atom densities as a function of the $H$ content in the films.

Higher $\mathrm{H}$ fluxes further lower the $s p^{1}$ content and strongly increase the $s p^{3}$ content, whereas the $s p^{2}$ content remains more or less constant. In this region, a considerable fraction of the film volume is taken by the $\mathrm{H}$ atoms, contributing only to the atom density, and hardly to the mass density. Hence, the films now become more porous and less dense.

At even higher $H$ fluxes $\left(\Phi_{\mathrm{H}, \text { rel }}>0.30\right)$, the $s p^{2}$ carbon atoms are converted into $s p^{3}$ carbons, coinciding with the maximum found in the atom density. As can be seen in Fig. 1 , the fraction of bulky $\mathrm{CH}_{2}$ groups now becomes important. These groups repel each other, such that from this point on, both the atom density and the mass density decrease. Hence, as the $\mathrm{H}$ flux towards the substrate increases, there is a H-induced $s p^{1}$ to $s p^{2}$ to $s p^{3}$ shift.

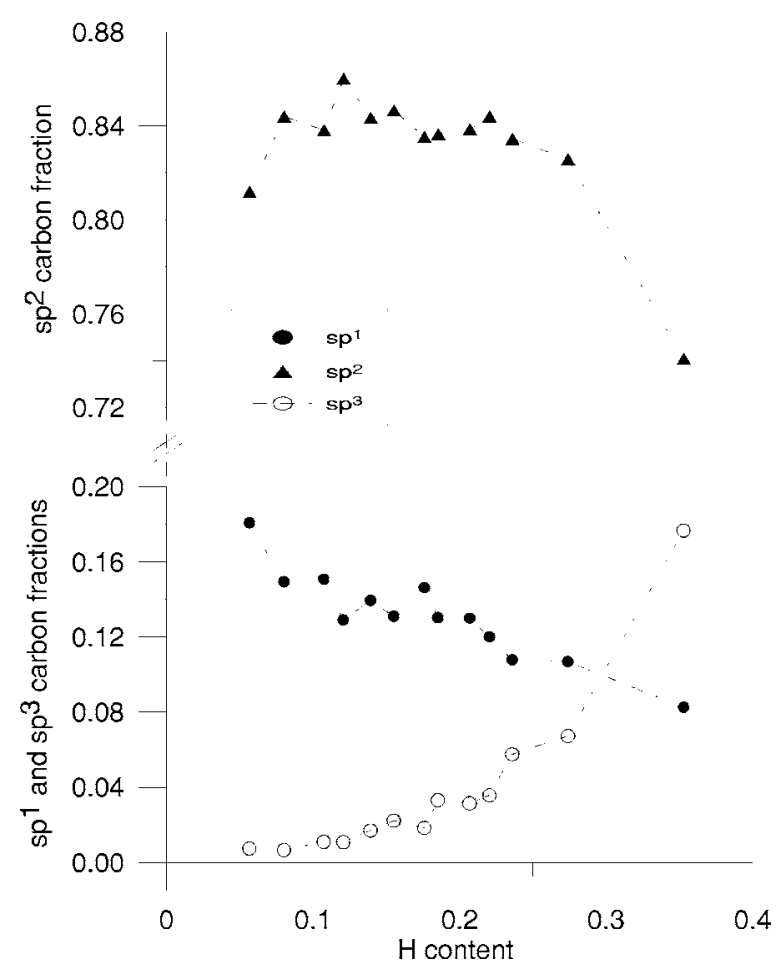

FIG. 3. Calculated $s p^{1}, s p^{2}$, and $s p^{3} \mathrm{C}$ fractions as a function of the $\mathrm{H}$ content in the films. 
The precision of our simulations is difficult to estimate, because the calculations are very time consuming, and it is not feasible to repeat them a few times every run. However, to check the precision of our simulations, two control runs were performed using $\mathrm{H}$ fluxes of $10 \%$ and $20 \%$, respectively. The fractional $\mathrm{H}$ contents in the two films produced using the $10 \% \mathrm{H}$ flux were 0.10 and 0.11 , while the procentual differences in mass density, atom density, $s p^{2}$ fraction and average C-coordination number are $0.90 \%, 1.64 \%$, $0.06 \%$, and $0.10 \%$. The $\mathrm{H}$ contents in the films produced using the $20 \% \mathrm{H}$ flux were 0.16 and 0.18 , while the procentual differences in mass density, atom density, $s p^{2}$ fraction, and average C-coordination number are $0.40 \%, 1.72 \%$, $1.67 \%$, and $0.25 \%$. These control runs therefore demonstrate the typical precision expected for the simulations.

In conclusion, the $\mathrm{H}$ uptake in the film is quasilinearly dependent on the $\mathrm{H}$ flux. At low $\mathrm{H}$ fluxes, some hydrogen is incorporated into the film, leading to an increase in the atom density. This also leads to a conversion of $s p^{1}$ to $s p^{2}$ carbon sites, coinciding with an increase in the mass density. The maximum mass density of $1.79 \mathrm{~g} \mathrm{~cm}^{-3}$ is found at a $\mathrm{H}$ content of about $10 \%$. Higher $\mathrm{H}$ fluxes bring more $\mathrm{H}$ into the film, leading to a higher atom density, but a lower mass density, while $s p^{1} \mathrm{C}$ sites are further converted to $s p^{2}$ sites, and $s p^{2}$ sites to $s p^{3}$ sites. Finally, at even higher H fluxes, the mass density keeps decreasing, and a maximum is found in the atom density, at a $\mathrm{H}$ flux of $30 \%$. From this point on, the $s p^{2}$ content starts to decrease, coinciding with a decrease in the atom density and an increase in the fraction of $\mathrm{CH}_{2}$ (see Fig. 1). Experimentally, a $\mathrm{H}$ content of about $33 \%$ and a mass density of about $1.5 \mathrm{~g} \mathrm{~cm}^{-3}$ were found, corresponding very well with our simulations.

From these results, the $\mathrm{H}$ flux towards the substrate can be estimated by measuring the $\mathrm{H}$ content in the films. Also, these results show how $a-\mathrm{C}: \mathrm{H}$ films, grown from low-kinetic energy radicals, can be densified using low $\mathrm{H}$ fluxes. These results are relevant for experimental deposition conditions where no ion bombardment is present, and show that even without ion bombardment densification is possible, by varying the $\mathrm{H}$ flux towards the substrate.

One of the authors (E.N.) is indebted to the Institute for the Promotion of Innovation by Science and Technology in Flanders (IWT-Flanders) for financial support. The authors would like to thank R. Gijbels and J. Benedikt for the many fruitful discussions.

${ }^{1}$ J. Robertson, Mater. Sci. Eng., R. 37, 129 (2002).

${ }^{2}$ T. Som, M. Malhotra, V. N. Kulkarni, and S. Kumar, Physica B 355, 72 (2005).

${ }^{3}$ A. C. Ferrari, A. Libassi, B. K. Tanner, V. Stolojan, J. Yuan, L. M. Brown, S. E. Rodil, B. Kleinsorge, and J. Robertson, Phys. Rev. B 62, 11089 (2000).

${ }^{4}$ E. Findeisen, R. Feidenhans, M. E. Vigild, K. N. Clausen, J. B. Hansen, M. D. Bentzon, and J. P. Goff, J. Appl. Phys. 76, 4636 (1994).

${ }^{5}$ D. W. Brenner, Phys. Rev. B 42, 9458 (1990).

${ }^{6}$ J. Tanaka, C. Abrams, and D. Graves, J. Vac. Sci. Technol. A 18, 938 (2000).

${ }^{7}$ E. Neyts, A. Bogaerts, R. Gijbels, J. Benedikt, and M. C. M. van de Sanden, Diamond Relat. Mater. 13, 1873 (2004).

${ }^{8}$ J. Benedikt, S. Agarwal, D. Eijkman, W. Vandamme, M. Creatore, and M. C. M. van de Sanden, J. Vac. Sci. Technol. A 23, 1400 (2005).

${ }^{9}$ E. Neyts, M. Tacq, and A. Bogaerts, Diamond Relat. Mater. (to be published). 